Dental Hospital (1858), and was instrumental in securing passage of the Dental Act (1878) for the compulsory education and registration of dentists'.

This brief biographical note from Garrison summarizes the well-known and essential achievements of the eminent Victorian who forms the principai figure in Sir Zachary Cope's account of the emergence of dentistry as a profession recognized as such by its part parent and sponsor, the Royal College of Surgeons, and the law. All the usual concomitants associated with the defining of a group within a group and the birth of a modern profession were present: rival bodies, splinter groups due to differing opinions on aims and strategy, acrimony and misunderstanding, lobbying and compromise. Holding the tale together is Tomes, great committee man, influential in high places, eloquent and skilled in diplomacy. Yet at the end of the hundred pages of well-written narrative we have learned nothing of his character save what is implicit in his varied activities, other than that he was 'a resolute man imbued with the seriousness of life', and the author freely admits the extreme paucity of information about his private life. Thus one is faced with the paradox of an undoubtedly great man whose biography consists almost solely of a catalogue of events, for lack of interesting character from the social, or literary viewpoint. Faced with such unpromising material the author has presented it competently and has avoided any tendency to pad a thin subject, exemplary, we hope, to those who, in the future, will undoubtedly pillage this work in the course of preparing a medico-dental oration.

\section{Management of Obstetric Difficulties}

Revised by J. RoBERT WILlson, M.D., M.S., sixth edition. Pp. 687, illustrated. St. Louis: C. V. Mosby Co. Distributed in Great Britain by Henry Kimpton, London. 196r. 123s. $6 d$.

This beautifully produced and well-illustrated edition maintains the high standard of its predecessors. Those who are not familiar with the book may be misled by its title. It is more than a guide to the management of obstetric difficulties and is, in fact, a valuable work of reference for students and practitioners. Emphasis is on clinical and practical details which are explained clearly and concisely, and for the student who wishes to consult original papers there is a well-chosen list of references at the end of each section.

The book is written in eight sections. The first deals with infertility and the last with the newborn infant. The remaining six are logically arranged to consider the diagnosis of pregnancy and antenatal care, complications of pregnancy, complications of labour, obstetric operations, complications of the puerperium and special therapy dealing with anæsthesia, analgesia, preparation for operation and special examinations.

An admirable account is given of the problems associated with the diagnosis and treatment of infertility, but the choice of films to illustrate hysterosalpingography findings is not good. Figures 9 and 10 claim to show normal tubal patency, but could well be used to illustrate tubal adhesions and peritubal loculation, and Figure I I could be demonstrating either organic occlusion or cornual spasm. The quality of the illustrations is excellent and this applies throughout the book.

This is a reference book which can be warmly recommended. It contains a wealth of valuable information carefully and wisely presented.

\section{Enzymes and Drug Action}

Ciba Foundation Symposium jointly with Co ordinating Committee for Symposia on Drug: Action. Edited by J. L. Mongar, PH.D., an A. V. S. DE ReuCK, M.SC., D.I.C. Pp. xv + 556\% with 90 illustrations. London: J. \& A. Churchilt I962. $65 s$.

A series of meetings was held between March 20 an 23, I 96 I, under the joint auspices of the Ciba Foundation and the Co-ordinating Committee for Symposia of Drug Action. The first part of the proceedings took the form of papers by well-known aithorities, followed by discussions, while the second part consisted entirely of unscripted discussions. The papers and the full discussions are printed in this volume.

Nineteen formal papers are presented under sios headings, 'Enzymes as Primary Points of Drug Action 'Active Transport', 'Multiple Mechanisms ', ' Recep?. tors ', 'Altered Drug Metabolism', and 'Drug Metaboitu ism: Subcellular Aspects'. A useful bibliography follows each paper. The unscripted discussions are under the general titles 'Drug-Enzyme Interaction at the Molew cular Level' and 'Drug-Enzyme Interaction at SubE cellular and Cellular Levels '. These sections contaip both summaries of experimental results and speculation about the underlying mechanisms.

The subject matter is presented mainly from the biochemical and biophysical viewpoints. The paperø are readable and are set out clearly, but some of the discussions, which appear to be reported verbatim could profitably have been edited into a less conversas tional form. One is left with the impression that, with one or two notable exceptions, much remains to be gis covered about the effects of drugs in relation to enzyries Nevertheless, much useful information is brough together in these pages, including theoretical considera tions which point the way to further experimental work

The clinician seeking up-to-date information of therapeutics will find little to interest him in this book However, to both biochemists and pharmacologists will provide a valuable source of reference both iळ relation to the particular topics discussed and as a guid to recent developments in techniques with more general application. The volume is clearly printed and we produced, with an adequate index.

\section{Renal Function}

IV. J. O'Connor, M.A., M.n. Pp. viii +24 . Illustrated. Monograph of the Physiologicad Society No. 10. London: Edward Arnold. 19623. 32s. 6d.

This publication is a presentation of renal function mainly from the point of view of agents which act of the kidney. Theories regarding intra-renal mechanisms are not discussed.

The material is presented in a clear manner. Thers. are descriptions of urinary changes resulting from changes in blood constituents and a discussion of the regulating mechanisms controlling water, electrolyte@ and $p \mathrm{H}$. There are numerous data charts which appeg rather small and some have too much material on theros to serve as illustrations.

The author is critical of many popular theories which in his view are substantiated by little or no experimental evidence. The style in general is facturis and the monograph would be of value to anyone interested in renal physiology. It presents the basi data stripped of speculation and verbal padding. 